\title{
Tuberculosis in seals caused by a novel member of the Mycobacterium tuberculosis complex: Mycobacterium pinnipedii sp. nov.
}

Debby V. Cousins, ${ }^{1}$ Ricardo Bastida, ${ }^{2}$ Angel Cataldi, ${ }^{3}$ Viviana Quse, ${ }^{4}$ Sharon Redrobe, ${ }^{5}$ Sue Dow, ${ }^{5}$ Padraig Duignan, ${ }^{6}$ Alan Murray, ${ }^{6}$ Christine Dupont, ${ }^{6}$ Niyaz Ahmed, ${ }^{7}$ Des M. Collins, ${ }^{8}$ W. Ray Butler, ${ }^{9}$ David Dawson, ${ }^{10}$ Diego Rodríguez, ${ }^{2}$ Julio Loureiro, ${ }^{3}$ Maria Isabel Romano, ${ }^{3}$ A. Alito, ${ }^{3}$ M. Zumarraga ${ }^{3}$ and Amelia Bernardelli ${ }^{11}$

Correspondence

Debby V. Cousins dcousins@agric.wa.gov.au
${ }^{1}$ Australian Reference Laboratory for Bovine Tuberculosis, Department of Agriculture Western Australia, 3 Baron-Hay Court, South Perth, WA 6151, Australia

${ }^{2}$ CONICET and Departamento de Ciencias Marinas, Facultad de Ciencias Exactas y Naturales, Universidad Nacional de Mar del Plata, Casilla de Correo 43, (7600) Mar del Plata, Argentina

${ }^{3}$ Instituto de Biotecnología, CICVyA, Instituto Nacional de Tecnología Agropecuaria, Los Reseros y Las Cabañas, (1712) Castelar, Argentina

${ }^{4}$ Fundación Mundo Marino, Avda Décima 157, (7105) San Clemente del Tuyú, Argentina

${ }^{5}$ Bristol Zoo Gardens, Bristol BS8 3HA, UK

${ }^{6}$ Pathobiology Group, Institute of Veterinary, Animal and Biomedical Sciences, Massey University, Private Bag 11-222, Palmerston North, New Zealand

${ }^{7}$ Centre for DNA Fingerprinting and Diagnostics (CDFD), Nacharam, Hyderabad 500076 , India

${ }^{8}$ AgResearch, Wallaceville Animal Research Centre, Upper Hutt, New Zealand

${ }^{9}$ Division of AIDS, STD and TB Laboratory Research, National Center for Infectious Diseases, Centers for Disease Control and Prevention, Atlanta, GA 30333, USA

${ }^{10}$ Mycobacterium Reference Laboratory, Queensland Health Pathology Services, Prince Charles Hospital, Chermside, Old 4032, Australia

${ }^{11}$ Departamento de Micobacterias, DILACOT, Servicio Nacional de Sanidad y Calidad Agroalimentaria (SENASA), Avda A Fleming 1653, (1640) Martínez, Argentina

A comparison of Mycobacterium tuberculosis complex isolates from seals (pinnipeds) in Australia, Argentina, Uruguay, Great Britain and New Zealand was undertaken to determine their relationships to each other and their taxonomic position within the complex. Isolates from 30 cases of tuberculosis in six species of pinniped and seven related isolates were compared to representative and standard strains of the $M$. tuberculosis complex. The seal isolates could be distinguished from other members of the M. tuberculosis complex, including the recently defined 'Mycobacterium canettii' and 'Mycobacterium caprae', on the basis of host preference and phenotypic and genetic tests. Pinnipeds appear to be the natural host for this 'seal bacillus', although the organism is also pathogenic in guinea pigs, rabbits, humans, Brazilian tapir (Tapirus terrestris) and, possibly, cattle. Infection caused by the seal bacillus is predominantly associated with granulomatous lesions in the peripheral lymph nodes, lungs, pleura, spleen and peritoneum. Cases of disseminated disease have been found. As with other members of the M. tuberculosis complex, aerosols are the most likely route of transmission. The name Mycobacterium pinnipedii sp. nov. is proposed for this novel member of the M. tuberculosis

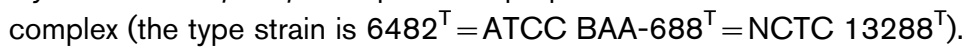

Published online ahead of print on 24 January 2003 as DOI 10.1099/ijs.0.02401-0.

Abbreviations: BCG, Bacille Calmette-Guérin; FAFLP, fluorescent amplified fragment length polymorphism; PZA, pyrazinamide; SS, seal spoligotype; $\mathrm{TCH}$, thiophen-2-carboxylic acid hydrazide.

The GenBank/EMBL/DDBJ accession number for the $16 \mathrm{~S}$ rRNA gene sequence of strain $6482^{\top}$ is AF502574. 


\section{INTRODUCTION}

The Mycobacterium tuberculosis complex has traditionally consisted of four members: M. tuberculosis (sensu stricto), which primarily infects human and primates; Mycobacterium bovis, which predominantly causes tuberculosis in cattle (Karlson \& Lessel, 1970), but can also cause disease in a wide variety of other animals, including man; M. bovis Bacille Calmette-Guérin (BCG), an attenuated strain that is used for vaccination; Mycobacterium africanum, a heterogeneous group of isolates responsible for human tuberculosis in Africa, which appears to be intermediate between M. tuberculosis and M. bovis (Castets et al., 1969); and Mycobacterium microti, a less frequently isolated pathogen that traditionally causes tuberculosis in voles (Wells \& Oxen, 1937; Wells \& Robb-Smith, 1946), but has been identified more recently as a cause of disease in immunocompromised humans (van Soolingen et al., 1998). Each member of the M. tuberculosis complex is associated with a specific primary host, although infection is known to occur in various alternative hosts. Although all of these strains effectively share the same 16S rRNA gene sequence (Rogall et al., 1990b) and high DNA-DNA homology (from hybridization studies), they can be separated by some phenotypic characteristics (Grange \& Yates, 1994) and, as they have different primary hosts, they have been regarded as separate species (Collins et al., 1982). More recently, two novel strains have been described: 'Mycobacterium canettii', a novel smooth variant of $M$. tuberculosis that was first isolated from a Somali-born patient (van Soolingen et al., 1997) and subsequently from a Swiss patient exposed in Africa (Pfyffer et al., 1998); and 'Mycobacterium caprae' (basonym: M. tuberculosis subsp. caprae), a strain that occurs primarily in Spanish goats and has recently been elevated to species level (Aranaz et al., 1999; Niemann et al., 2002; Aranaz et al., 2003). M. tuberculosis, M. africanum, M. microti and M. bovis were accepted as separate species by using a combination of phenotypic characteristics and apparent host specificity. 'M. canettii' and 'M. caprae' were accepted by virtue of host preference and phenotypic and genetic characteristics.

Previous logical arguments have suggested that all members of the $M$. tuberculosis complex are sufficiently similar to belong to the species M. tuberculosis (Wayne, 1984; Tsukamura et al., 1985; van Soolingen et al., 1997). Acceptance of such an approach would cause currently accepted species (M. bovis, M. microti and M. africanum) to warrant classification at the subspecies level.

Between 1986 and 1995, M. tuberculosis complex organisms were isolated from cases of tuberculosis in captive or wild Australian sea lions (Neophoca cinerea), New Zealand fur seals (Arctocephalus forsteri), an Australian fur seal (Arctocephalus pusillus doriferus) and a seal trainer who worked with the affected colony in Australia (Forshaw \& Phelps, 1991; Thompson et al., 1993; Cousins, 1995; Woods et al., 1995). Similar organisms were recovered from captive Southern sea lions (Otaria flavescens), wild South American fur seals (Arctocephalus australis) and a wild Subantarctic fur seal (Arctocephalus tropicalis) in Uruguay or Argentina during the period 1989-2000 (Bernardelli et al., 1994, 1996; Castro Ramos et al., 1998; Bastida et al., 1999). Between 1996 and 1998, M. tuberculosis complex organisms were recovered from two South American fur seals in a zoological collection in Great Britain and a Brazilian tapir (Tapirus terrestris) housed in an adjacent enclosure, and from two New Zealand fur seals in New Zealand in 1997 and 1998 (Hunter et al., 1998).

Many of the isolates obtained from cases of tuberculosis in Australia, Uruguay and Argentina have been wellcharacterized (Cousins et al., 1993; Bernardelli et al., 1996; Cousins, 1996; Alito et al., 1999; Zumárraga et al., 1999) and this information, together with preliminary tests on the seal isolates from Great Britain and New Zealand, suggested that the seal bacillus (Cousins et al., 1993), isolated from pinnipeds from all four continents, may be a unique member of the M. tuberculosis complex. A recent study of four Australian and six Argentinian seal isolates by fluorescent amplified fragment length polymorphism (FAFLP) has further substantiated the hypothesis that the seal bacillus occupies a unique taxonomic position within the M. tuberculosis complex (Ahmed et al., 2003). This report consolidates the results of tests performed previously and provides additional information, resulting in a comprehensive comparison of isolates available from pinniped-related cases of tuberculosis, and indicates that the seal bacillus should be considered as a novel species of the M. tuberculosis complex.

\section{METHODS}

Bacterial strains. $M$. tuberculosis complex isolates recovered from 30 pinnipeds and a seal trainer from 1985 to 2000 were available for study (Table 1). Isolates recovered from two guinea pigs and two rabbits after pathogenicity experiments in Australia, a bovine in New Zealand (this isolate had a restriction endonuclease analysis pattern similar to those of the Australian seal isolates) and a Brazilian tapir were also included. Where appropriate, isolates were compared to representative (and reference) strains of $M$. tuberculosis (H37Rv or Mt14323), M. africanum (TMC3), 'M. caprae' (CIP $105776^{\mathrm{T}}$ ), M. microti (NCTC $8710^{\mathrm{T}}$ ), M. bovis (AN5) and M. bovis BCG (P3) (Table 2).

Phenotypic characteristics. Isolates were examined for growth and phenotypic characteristics according to standard procedures (Vestal, 1975). In vitro susceptibility patterns to isoniazid, rifampicin, streptomycin and ethambutol were determined for three isolates from Australia, three from Argentina, one from Uruguay, two from Great Britain and two from New Zealand by using the Mycobacterial Growth Indicator Tube (MGIT; Becton Dickinson) system (Bernardelli et al., 1999; Morcillo et al., 2000).

Pathogenicity studies in guinea pigs and rabbits. Isolates from two Australian seals (Au-1 and Au-2) were each injected into a guinea pig and a rabbit, and three isolates from Argentina (Ar-1, Ar-2 and Ar-3) and the isolate from Uruguay (U-1) were inoculated into guinea pigs, to examine the pathogenicity of the seal isolates. 
Table 1. M. tuberculosis complex isolates recovered from pinnipeds or related cases from various countries, $1985-2000$

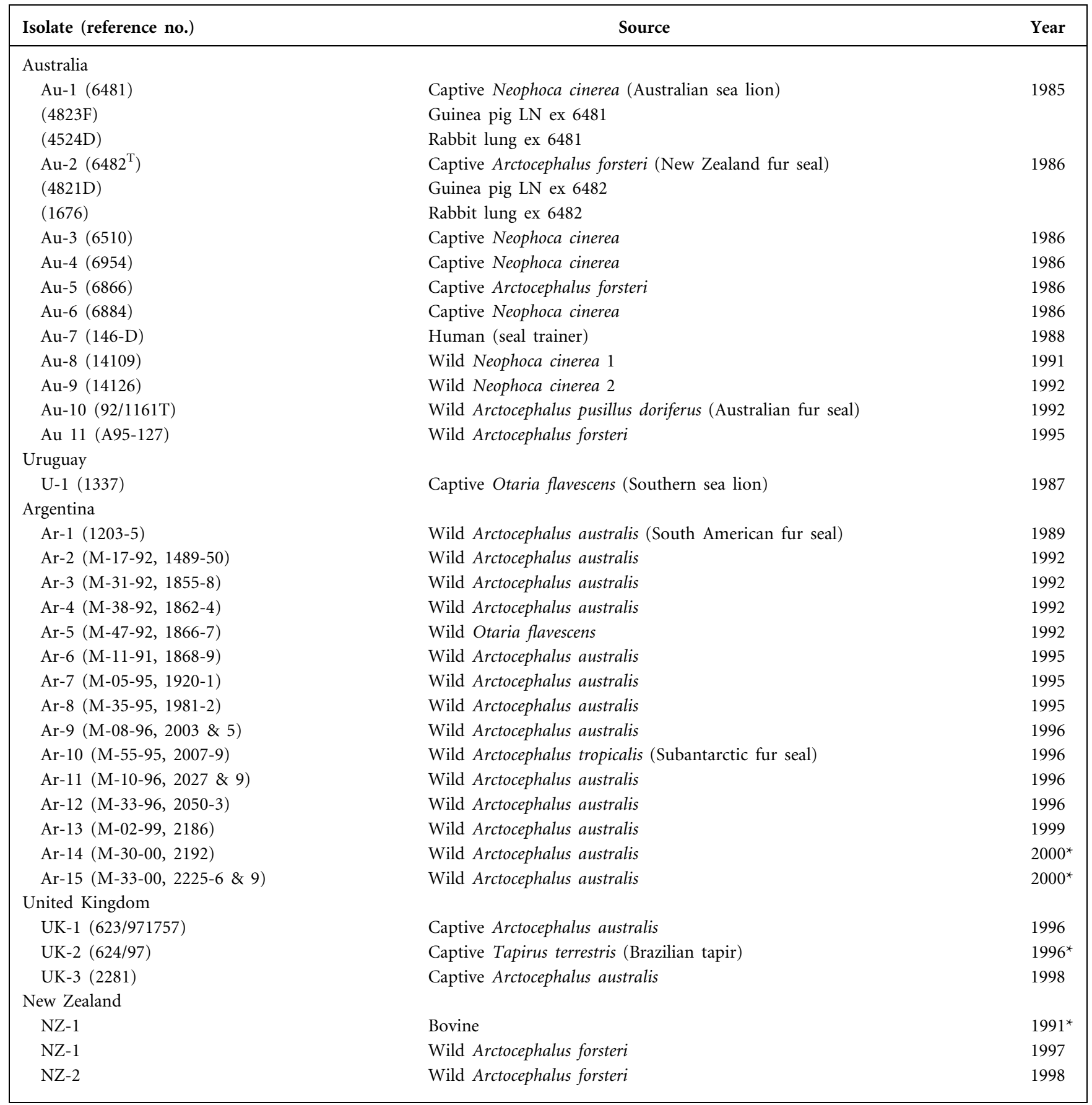

${ }^{*}$ Unpublished.

Mycolic acid analysis. Mycolic acid profiles of two representative isolates (Au-1 and $\mathrm{Au}-2)$ were examined by HPLC, according to previously published procedures (Butler et al., 1996, 1999).

Tests for MPB70. All isolates were tested for the presence of the MPB70 antigen either by using the immunoperoxidase test (Corner et al., 1988; Veerman et al., 1990; Liébana et al., 1996) and/or by performing SDS-PAGE on antigen preparations (Cousins et al., 1993; Alito et al., 1999).
165 rDNA sequence determination and PCR-based tests for genetic markers. PCR-mediated amplification of $16 \mathrm{~S}$ rDNA was performed by using procedures described previously (Edwards et al., 1989; Kirschner et al., 1993). The nucleotide sequences obtained were compared to all known 16S rDNA mycobacterial sequences in GenBank and the M. bovis sequence (available at the Sanger website, http://www.sanger.ac.uk/Projects/M_bovis/) by using the FastA application. Sequences were aligned with the program PILEUP from the Genetics Computer Group (GCG) version 9 UNIX software 
Table 2. $M$. tuberculosis complex isolates that were tested by spoligotyping and used to prepare the dendrogram (Fig. 2)

AFS, Australian fur seal; ASL, Australian sea lion; Bj, Beijing strain; COB, country of birth; NZFS, New Zealand fur seal; SAFS, South American fur seal; TMC, Trudeau Mycobacterium Collection.

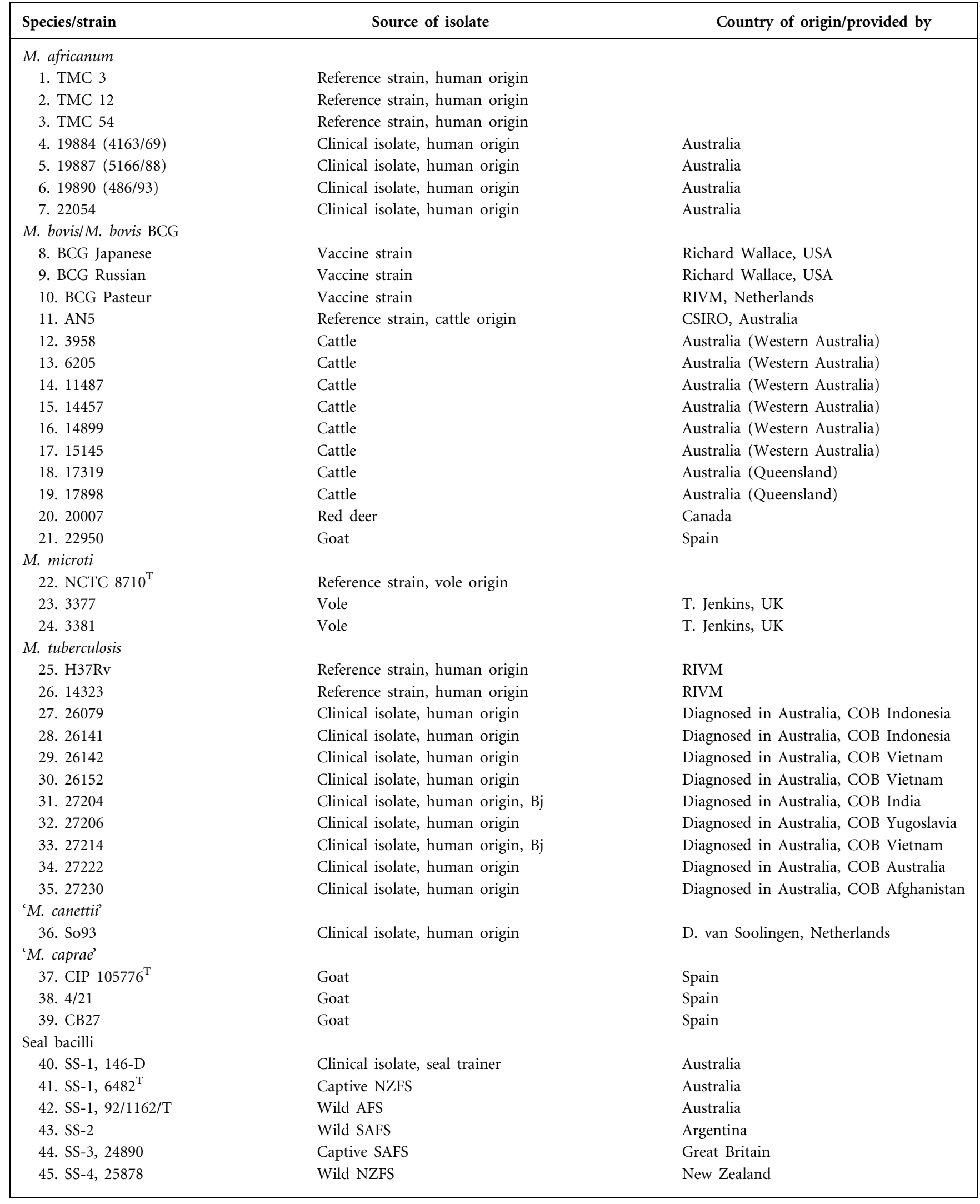


package. Phylogenetic analyses of the sequence data were done with programs from the Phylogeny Inference Package (PHYLIP) as described previously (Floyd et al., 1996). The pairwise comparison program GAP, also from the GCG package, was used to determine the position of consensus strand nucleotides, relative to those of Escherichia coli (GenBank number J01859). The 16S rDNA sequence of strain $6482^{\mathrm{T}}$ was deposited in GenBank under accession number AF502574.

PCR-based tests for known genetic markers. All isolates were tested by PCR for the presence of mycobacterial 16S rDNA, the gene that encodes the MPB70 antigen, the IS6110, IS1081 and mtp40 sequences (Del Portillo et al., 1991) and the $\mathrm{P}_{\mathrm{AN}}$ promoter region that is present in pathogenic mycobacteria (Gormley et al., 1997) by using previously published methods (Liébana et al., 1996; Zumárraga et al., 1999). Representative isolates were tested for $\mathrm{kat} G$ and $\mathrm{gyrA}$ gene sequence polymorphisms at codons 463 and 95, respectively, by using methods described previously (Zumárraga et al., 1999). Allelespecific polymorphisms were examined at nt 285 of the oxyR gene (Sreevatsan et al., 1996), which differentiates M. bovis and 'M. caprae' (adenine) from other members of the M. tuberculosis complex (guanidine), and in codon 57 (nt 169) of the pncA gene, which is responsible for pyrazinamide (PZA) resistance (Espinosa de los Monteros et al., 1998), which is consistent with M. bovis.

Spoligotyping. All but two isolates were tested for known spacers between direct repeats in the DR allele by using the spoligotyping method developed by Kamerbeek et al. (1997) and performed as described previously (Aranaz et al., 1996; Zumárraga et al., 1999). Spoligotyping results were analysed by electronic scanning of images and converting and analysing them by using GelCompar version 1.3, as described previously (Romano et al., 1995; Cousins et al., 1998a, b). The patterns obtained from the South American isolates were compared to a database that consisted mostly of $M$. bovis isolates from Argentina. In addition, the patterns obtained from all seal isolates were compared with a large database of patterns that contained approximately $700 \mathrm{M}$. tuberculosis complex isolates, including approximately 500 M. bovis isolates from cattle, buffalo, deer, wild animals and humans from Australia and other countries (Cousins et al., 1998a); they were also compared to the CDC database (Jack
Crawford, personal communication). The seal isolates and representative and reference strains of the M. tuberculosis complex (Table 2) were included in a dendrogram of spoligotype patterns that were generated by using Dice UPGMA analysis (GelCompar, version 3.1; Applied Maths) to examine the clonal relationships between them.

FAFLP. Heat-killed cells of isolates from three Australian sea lions, one Australian fur seal and six South American fur seals were digested by using EcoRI/MseI and analysed by FAFLP, using methods described previously (Ahmed et al., 2002, 2003). Analyses were based on the differential amplification of 131 genomic loci. Standard genomic DNA from $M$. tuberculosis H37Rv, M. bovis AN5, M. africanum and M. microti (NCTC $8710^{\mathrm{T}}$ ) was used for comparative FAFLP analysis.

\section{RESULTS AND DISCUSSION}

\section{Morphology, growth and phenotypic characteristics of seal isolates}

A description of the physiological characteristics of the taxon can be found in the formal description. Biochemical testing clearly confirmed that the seal isolates belonged to the $M$. tuberculosis complex. The negative reactions in the nitrate reduction and niacin accumulation tests were consistent with M. bovis (Grange \& Yates, 1994) (Table 3), a fact that led to their initial identification as such in Australia (Forshaw \& Phelps, 1991), Argentina (Bernardelli et al., 1996) and Great Britain. In some cases, varying amounts of niacin were produced, which is similar to results reported for M. africanum (Grange \& Yates, 1994). In most cases, the seal isolates grew preferentially on media that contained sodium pyruvate, although some (including NZ2 and NZ-3) also grew on Löwenstein-Jensen medium that contained glycerol. Slight differences from typical M. bovis isolates were noted in Australia and Argentina, in that the

Table 3. Phenotypic properties of the seal bacillus, compared to other members of the M. tuberculosis complex

Species: 1, M. tuberculosis (classic); 2, M. tuberculosis (Asian); 3, M. africanum (type I); 4, M. africanum (type II); 5, M. microti; 6, seal bacillus; 7, M. bovis; 8, 'M. caprae'; 9, M. bovis BCG. Data were taken from references cited in the text. Abbreviations: + , positive; -, negative; $\mathrm{V}$, variable; NA, not applicable.

\begin{tabular}{|c|c|c|c|c|c|c|c|c|c|}
\hline Characteristic & 1 & 2 & 3 & 4 & 5 & 6 & 7 & 8 & 9 \\
\hline Nitrate reduction & + & + & - & + & - & - & - & - & - \\
\hline Niacin accumulation & + & + & $\mathrm{v}$ & $\mathrm{v}$ & + & $-*$ & - & - & - \\
\hline Pyruvate preference & - & - & - & - & - & + & + & + & + \\
\hline Stimulated by glycerol & + & & - & - & - & - & - & - & + \\
\hline MPB70 antigen & - & - & - & - & - & - & + & $?$ & + \\
\hline \multicolumn{10}{|l|}{ Resistance to: } \\
\hline $\mathrm{TCH}$ & + & - & - & + & - & $-\dagger$ & - & - & - \\
\hline PZA & - & - & - & - & - & - & + & - & + \\
\hline \multicolumn{10}{|l|}{ Pathogenicity in: } \\
\hline Guinea pig & ++ & & ++ & & - & ++ & ++ & NA & - \\
\hline Rabbit & - & & $+1-$ & & - & +++ & ++ & NA & - \\
\hline
\end{tabular}

${ }^{*}$ Occasional strains, including the isolates from New Zealand, gave weak or positive reactions in the niacin accumulation test.

$\dagger$ New Zealand strains were resistant to $1 \mu \mathrm{g} \mathrm{TCH} \mathrm{ml}{ }^{-1}$, but sensitive to $10 \mu \mathrm{g} \mathrm{TCH} \mathrm{ml}{ }^{-1}$.

$\ddagger$ Resistant to 1 and $2 \mu \mathrm{g} \mathrm{TCH} \mathrm{ml} l^{-1}$, but sensitive to 5 and $10 \mu \mathrm{g} \mathrm{TCH} \mathrm{ml}{ }^{-1}$. 
cord formation observed after Ziehl-Neelsen staining was loose; further investigations uncovered differences between the seal isolates and M. bovis, including its susceptibility to PZA.

\section{Pathogenicity and potential host range}

Isolates inoculated into guinea pigs produced significant lesions or death within 6 weeks and those inoculated into rabbits caused death within 6 weeks, confirming that the isolates were fully virulent in both laboratory animals. The finding of a bovine isolate in New Zealand with characteristics indistinguishable from those of isolates from fur seals in New Zealand waters suggests that the seal bacillus is also capable of infecting cattle. This fact, combined with knowledge of its ability to cause disease in humans (Thompson et al., 1993) and tapirs, suggests that the seal bacillus has the potential for a host range that extends beyond those of $M$. tuberculosis, M. africanum and M. microti.

\section{Mycolic acid analysis}

HPLC chromatograms of isolates $\mathrm{Au}-1$ and $\mathrm{Au}-2$ demonstrated a single cluster pattern that was consistent with species of the M. tuberculosis complex (data not shown) as reported previously (Butler et al., 1991), providing additional evidence that these organisms belonged to the M. tuberculosis complex.

\section{Tests for the MPB70 antigen}

All seal isolates were negative when tested for the MPB70 antigen, despite containing the $m p b 70$ gene. The MPB70 antigen is considered to be characteristic of $M$. bovis (Corner et al., 1988; Liébana et al., 1996) and can be demonstrated by dot-blot immunoperoxidase (Liébana et al., 1996) or SDS-PAGE (Cousins, 1996; Alito et al., 1999). In a previous study, $>97 \%$ of M. tuberculosis isolates, $100 \%$ of M. microti isolates and $90 \%$ of $M$. africanum isolates were negative for the MPB70 antigen, whereas $>99 \%$ of M. bovis isolates were positive (Liébana et al., 1996). In this regard, the seal bacillus was more like other members of the M. tuberculosis complex than $M$. bovis. The reported presence of the MPB70 antigen in a single isolate of M. microti from an alpaca (Alito et al., 1999) was contrary to the findings of Liébana et al. (1996), who tested seven isolates of M. microti (including the reference strain).

\section{$16 S$ rDNA sequence determination}

$16 \mathrm{~S}$ rDNA sequencing is an accepted method of confirming the species designation of mycobacterial isolates (Böddinghaus et al., 1990; Rogall et al., 1990a, b). The $16 \mathrm{~S}$ rDNA consensus strand (1400 nt) from the seal isolates demonstrated $99.9 \%$ similarity to those of $M$. tuberculosis (GenBank number X58890) and M. bovis (available from the Sanger website at http://www.sanger.ac.uk/Projects/ M_bovis/). A single nucleotide substitution $(\mathrm{C} \rightarrow \mathrm{T})$ in the consensus strand occurred at E. coli position 1256 (data not shown). Phylogenetic analysis demonstrated that the consensus sequence was on the same branch as that of M. tuberculosis. The 16S rDNA regions of the isolates that were sequenced $(1030 \mathrm{bp})$ were consistent with the sequence of the M. tuberculosis complex.

\section{PCR-based testing of genetic markers}

The gyrA and kat $G$ gene sequences of all seal isolates were identical (Table 4). These genetic markers are accepted methods of confirming that isolates belong to the M. tuberculosis complex (Thierry et al., 1990, 1993;

Table 4. Genetic properties of the seal bacillus, compared to other members of the M. tuberculosis complex

Species: 1, M. tuberculosis (classic); 2, M. tuberculosis (Asian); 3, M. africanum (type I); 4, M. africanum (type II); 5, M. microti; 6, seal bacillus; 7, M. bovis; 8, 'M. caprae'; 9, M. bovis BCG. All species contain IS6110 and IS1081, although some Asian strains of M. tuberculosis lack IS6110. Present (1-5), between one and five of the 3' spacers (39-43) are present; NIL, none of the five 3' spacers (39-43) are present.

\begin{tabular}{|c|c|c|c|c|c|c|c|c|c|}
\hline Locus & 1 & 2 & 3 & 4 & 5 & 6 & 7 & 8 & 9 \\
\hline$m t p 40$ & $+^{*}$ & + & $+^{*}$ & $+^{*}$ & $-\dagger$ & + & - & - & - \\
\hline pncA C57 & CAC (His) & $\mathrm{CAC}$ & CAC & CAC & CAC & CAC & $\begin{array}{l}\text { GAC } \\
\text { (Asp) }\end{array}$ & CAC & GAC \\
\hline katG $\mathrm{C} 463$ & $\begin{array}{l}\text { CTG (Leu), } \\
\text { CGG (Arg) }\end{array}$ & $\begin{array}{l}\text { CTG/ } \\
\text { CGG }\end{array}$ & CTG & CTG & CTG & CTG & CTG & CTG & CTG \\
\hline oxyR nt 285 & G & G & G & G & G & G & A & A & A \\
\hline gyrA C95 & $\begin{array}{l}\text { AGC (Ser), } \\
\text { ACC (Thr) }\end{array}$ & - & ACC & ACC & ACC & ACC & ACC & ACC & ACC \\
\hline Spoligotyping: spacers $39-43$ & Present $(1-5)$ & & $\begin{array}{c}\text { Present } \\
(1-5)\end{array}$ & & NIL & NIL & NIL & NIL & NIL \\
\hline
\end{tabular}

${ }^{\star}$ Very occasionally, members of these species lack the mtp40 gene (Liébana et al., 1996).

$\dagger$ Seven of seven isolates $(100 \%)$ were negative for mtp40 (Liébana et al., 1996), whereas one isolate tested by Bernardelli et al. (1996) was reported as positive. 


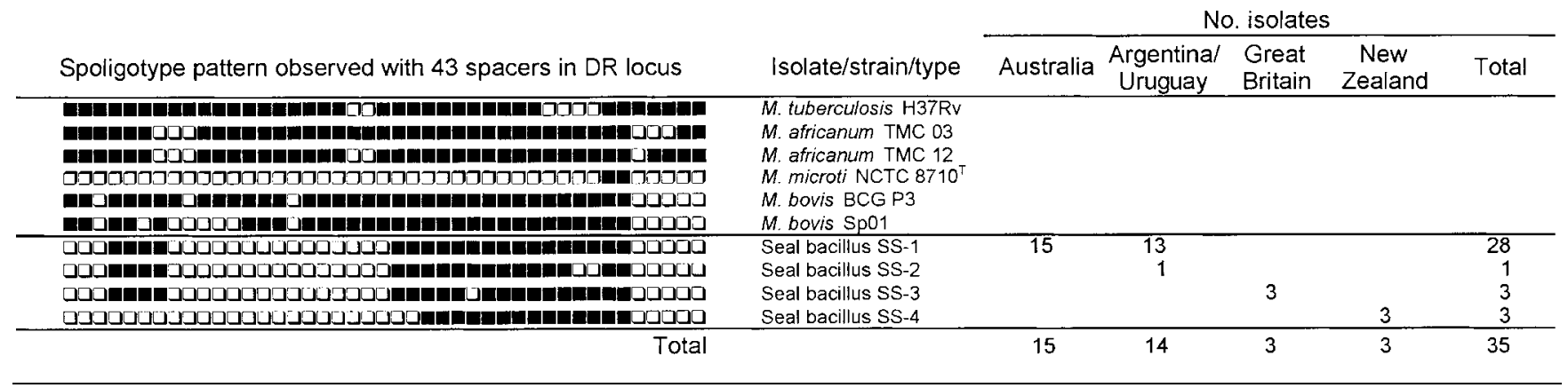

Fig. 1. Results of spoligotyping of seal-related isolates from Australia, Uruguay, Argentina, Great Britain and New Zealand, compared to reference strains of the M. tuberculosis complex. $\mathbf{\square}$, Hybridization with spacer; $\square$, no hybridization with spacer. NCTC, National Collection of Type Cultures; TMC, Trudeau Mycobacterium Collection.

Collins \& Stephens, 1991; Cousins et al., 1991; Groenen et al., 1993; Liébana et al., 1996; Gormley et al., 1997; Sreevatsan et al., 1997). Results from sequencing of the $m t p 40, p n c A$ and $\operatorname{oxyR}$ genes clearly demonstrated that the seal isolates were genetically more consistent with M. tuberculosis and M. africanum than with M. bovis.

\section{DNA spoligotyping}

Four different spoligotypes were identified in the seal isolates; all lacked the spacers 39-43, which are known to be characteristic of $M$. bovis (Fig. 1). All of the isolates from Australia and all but one of the Argentinian isolates had a unique but identical pattern, designated seal spoligotype 1 (SS-1). The remaining Argentinian isolate was designated SS-2. The three isolates from Great Britain had identical spoligotypes (SS-3) that differed by one spacer from the other seal spoligotypes. The seal isolates from New Zealand and the isolate from a New Zealand bovine had identical spoligotypes (SS-4) that lacked six spacers that were present in all other seal isolates. When compared to reference (and representative) strains of M. tuberculosis, M. africanum, M. microti, M. bovis, ' $M$. canettii' and ' $M$. caprae', the seal isolates formed a distinct cluster within the M. tuberculosis complex (Fig. 2). Spoligotyping confirmed that the seal isolates from Australia, Argentina, Uruguay and Great Britain were closely related. The finding of three spoligotypes with only minor differences from 29 isolates that originated from these diverse geographical regions indicated a clonal relationship between these isolates, which in turn suggests that the infection may have originated from a single source as a relatively recent event. Considering that these cases were diagnosed over a period of more than 15 years and that many of these populations inhabit geographically separate territories, a more likely explanation is that the DR locus exhibits considerable genetic stability in the seal bacillus. The spoligotype identified in the New Zealand isolates clustered with those of the other seal isolates but was genetically further removed, confirming a closer relationship to the other seal isolates than to other members of the M. tuberculosis complex. Similar small differences in spoligotype were evident among a group of ' $M$. caprae' isolates (Aranaz et al., 1999). Spoligotyping has previously been used to define clonal relationships of the Beijing family of M. tuberculosis (van Soolingen et al., 1995; Qian

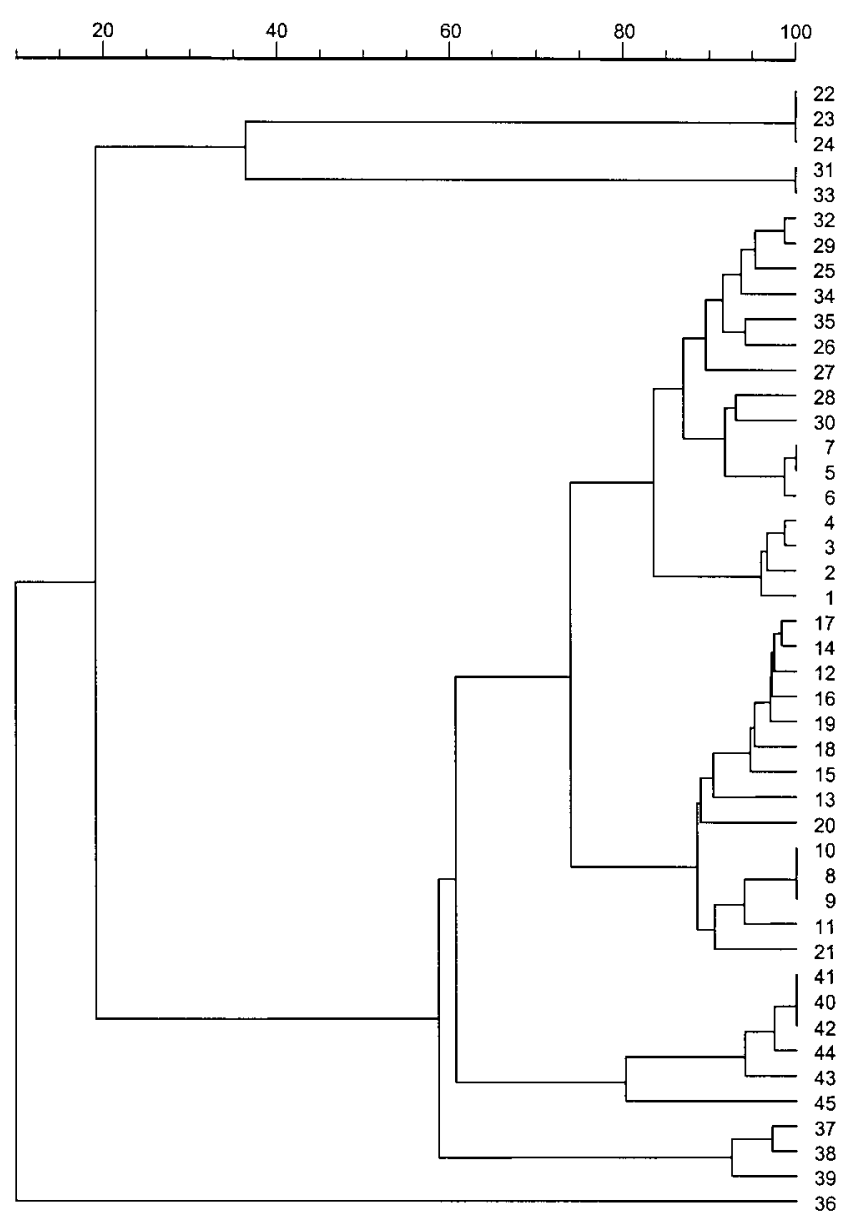

Fig. 2. Dendrogram showing the relationship of established members of the M. tuberculosis complex and the seal bacillus, as revealed by spoligotyping. Strain designations are given in Table 2. 
et al., 1999; Anh et al., 2000) and has been used to trace the global spread of this strain. It has also been proved to be useful in defining populations of M. microti (van Soolingen et al., 1998) and, in this study, demonstrated its usefulness in defining the limited genetic diversity of the seal bacillus.

Dendrograms constructed by using GelCompar indicated there was a close relationship between all seal-related isolates. Other methods of typing these isolates, including RFLP analysis with IS1081, IS6110, DR, PGRS and pUCD and VNTR (variable number of tandem repeats) typing, confirmed these findings (data not shown). Many investigators accept that members of the M. tuberculosis complex may be represented along a continuum with major peaks that correspond to each of the designated species. It is probable that the seal bacillus has evolved from another M. tuberculosis complex organism and has found a unique niche in this marine host. A study by Behr \& Small (1999) that identified deletion events in M. bovis BCG has elicited information on the evolution of BCG strains. Similar evolutionary insights into the origin of the seal bacillus have been gained by using comparative genomic technologies that were described previously (Brosch et al., 2002; Mostowy et al., 2002). In both studies, the seal strain was separated from classical M. bovis by at least six deletions. The seal bacillus has a similar number of deletions to $M$. microti and Brosch et al. (2002) suggest that, along with M. microti and ' $M$. canettii', the seal bacillus contains a unique deletion. These deletion studies provide further evidence that the seal bacillus should be designated as a separate species within the M. tuberculosis complex.

\section{FAFLP}

All 10 seal isolates produced indistinguishable results. When compared to the published sequences of $M$. tuberculosis strains CDC1551 and H37Rv and M. bovis strain AN5, up to 18 highly polymorphic FAFLP markers for the rapid identification of the seal bacillus were identified. In these studies, three loci appeared to be unique to the seal bacillus, 12 were shared with $M$. bovis and three were shared with M. tuberculosis. Further studies that include some of these loci may result in the identification of species-specific markers that are potentially useful for the development of PCR-based diagnostics for the seal bacillus. The identical genotype of all seal isolates that were tested by FAFLP confirmed their close clonal relationship, which had been identified by spoligotyping. It also substantiated previous studies that used FAFLP, which suggested that this technique may play a role in discriminating between mycobacterial species, including members of the $M$. tuberculosis complex (Goulding et al., 2000; Huys et al., 2000).

\section{Description of Mycobacterium pinnipedii sp. nov.}

Mycobacterium pinnipedii (pin.ni.pe'di.i. N.L. gen. neut. n. pinnipedii of a pinniped, referring to the host animal from which the organism was first isolated).
Isolates can be recovered from the lung and associated lymph nodes of tuberculous pinnipeds, and occasionally from mesenteric lymph nodes and organs such as the liver. Acid/alcohol-fast, non-spore-forming, non-motile bacilli with loose cord formation. Growth is generally enhanced by sodium pyruvate and usually occurs within 3-6 weeks of incubation on egg-based media at $36-37^{\circ} \mathrm{C}$. Colonies are dysgonic, rough, flat and non-photochromogenic. Isolates are negative for nitrate reduction and generally negative for niacin accumulation; some isolates demonstrate low-tomedium reactions for niacin. Susceptible to $50 \mu \mathrm{g} \mathrm{PZA} \mathrm{ml}^{-1}$ and $1 \mu \mathrm{g}$ thiophen-2-carboxylic acid hydrazide $(\mathrm{TCH}) \mathrm{ml}^{-1}$ (isolates have occasionally demonstrated resistance to $1 \mu \mathrm{g}$ $\mathrm{TCH} \mathrm{ml}{ }^{-1}$, but are susceptible to $10 \mu \mathrm{g} \mathrm{ml}^{-1}$ ). Pathogenic in guinea pigs and rabbits; the apparent incidental infection of a human, bovine and tapir indicates that they may have a wide host range. All isolates contain the sequences IS6110, IS 1081, $m p b 70$ and $m t p 40$, yet fail to produce detectable MPB70 antigen. The pncA gene contains CAC (His) at codon 57 and the $\operatorname{oxy} R$ gene shows G at nt 285, similar to M. tuberculosis, M. microti and M. africanum. The seal isolate spoligotypes form a cluster that is clearly different from those of all other members of the M. tuberculosis complex. The isolates are susceptible to isoniazid, rifampicin, streptomycin, ethambutol and paraminosalicylic acid.

The type strain is $6482^{\mathrm{T}}\left(=\mathrm{ATCC}\right.$ BAA $-688^{\mathrm{T}}=\mathrm{NCTC}$ $13288^{\mathrm{T}}$ ).

\section{ACKNOWLEDGEMENTS}

This work received financial support from the Brucellosis and Tuberculosis Eradication Campaign and the Tuberculosis Freedom Assurance Program within Australia. We are grateful to Fundación Mundo Marino, San Clemente del Tuyú, Argentina, for their support and to Frank Haverkort for his assistance with susceptibility testing and supplying M. tuberculosis isolates. We thank Dr Hans G. Trüper for advice on the Latin name of the organism.

\section{REFERENCES}

Ahmed, N., Bal, A., Khan, A. A. \& 9 other authors (2002). Whole genome fingerprinting and genotyping of multiple drug resistant (MDR) isolates of Pseudomonas aeruginosa from endophthalmitis patients in India. Infect Genet Evol 1, 237-242.

Ahmed, N., Alam, M., Abdul Maajeed, A., Asad Rahman, S., Cataldi, A., Cousins, D. \& Hasnain, S. E. (2003). Genome sequence based, comparative analysis of the fluorescent amplified fragment length polymorphisms (FAFLP) of tubercle bacilli from seals provides molecular evidence for a new species within the Mycobacterium tuberculosis complex. Infect Genet Evol 2, 193-199.

Alito, A., Romano, M. I., Bigi, F., Zumarraga, M. \& Cataldi, A. (1999). Antigenic characterization of mycobacteria from South American wild seals. Vet Microbiol 68, 293-299.

Anh, D. D., Borgdorff, M. W., Van, L. N., Lan, N. T., van Gorkom, T., Kremer, K. \& van Soolingen, D. (2000). Mycobacterium tuberculosis Beijing genotype emerging in Vietnam. Emerg Infect Dis 6, 302-305. 
Aranaz, A., Liébana, E., Mateos, A. \& 8 other authors (1996). Spacer oligonucleotide typing of Mycobacterium bovis strains from cattle and other animals: a tool for studying epidemiology of tuberculosis. J Clin Microbiol 34, 2734-2740.

Aranaz, A., Liébana, E., Gómez-Mampaso, E. \& 8 other authors (1999). Mycobacterium tuberculosis subsp. caprae subsp. nov.: a taxonomic study of a new member of the Mycobacterium tuberculosis complex isolated from goats in Spain. Int J Syst Bacteriol 49, 1263-1273.

Aranaz, A., Cousins, D., Mateos, A. \& Dominguez, L. (2003). Elevation of Mycobacterium tuberculosis subsp. caprae Aranaz et al. 1999 to species rank as Mycobacterium caprae comb. nov., sp. nov. Int J Syst Evol Microbiol (in press).

Bastida, R., Loureiro, J., Quse, V., Bernardelli, A., Rodriguez, D. \& Costa, E. (1999). Tuberculosis in a wild subantarctic fur seal from Argentina. J Wildl Dis 35, 796-798.

Behr, M. A. \& Small, P. M. (1999). A historical and molecular phylogeny of BCG strains. Vaccine 17, 915-922.

Bernardelli, A., Loureiro, J., Costa, E., Cataldi, A., Bastida, R. \& Michelis, H. (1994). Tuberculosis in fur seals and sea lions of the south western Atlantic coast. In IUATLD Newsletter, May 1994. Paris: International Union Against Tuberculosis and Lung Disease.

Bernardelli, A., Bastida, R., Loureiro, J., Michelis, H., Romano, M. I., Cataldi, A. \& Costa, E. (1996). Tuberculosis in sea lions and fur seals from the south-western Atlantic coast. Rev Sci Tech 15, 985-1005.

Bernardelli, A., Trovero, A., Loureiro, J., Quse, V. \& Morcillo, N. (1999). Sensibilidad in vitro a tuberculostáticos de cepas del complejo Mycobacterium tuberculosis aisladas en mamíferos marinos. In Abstracts of the XX Congresso Brasileiro de Microbiologia, p. 427, abstract SM-057. October 1999, Salvador, Brazil (in Portuguese).

Böddinghaus, B., Rogall, T., Flohr, T., Blöcker, H. \& Böttger, E. C. (1990). Detection and identification of mycobacteria by amplification of rRNA. J Clin Microbiol 28, 1751-1759.

Brosch, R., Gordon, S. V., Marmiesse, M. \& 12 other authors (2002). A new evolutionary scenario for the Mycobacterium tuberculosis complex. Proc Natl Acad Sci U S A 99, 3684-3689.

Butler, W. R., Jost, K. C., Jr \& Kilburn, J. O. (1991). Identification of mycobacteria by high-performance liquid chromatography. J Clin Microbiol 29, 2468-2472.

Butler, W. R., Floyd, M. M., Silcox, V. \& 9 other editors (1996). Standardized Method for HPLC Identification of Mycobacteria, pp. 3-22. Atlanta, GA: Centers for Disease Control and Prevention.

Butler, W. R., Floyd, M. M., Silcox, V. \& 9 other editors (1999). Mycolic Acid Pattern Standards for HPLC Identification of Mycobacteria, pp. 3-10. Atlanta, GA: Centers for Disease Control and Prevention.

Castets, M., Rist, N. \& Boisvert, H. (1969). La variété africaine du bacille tuberculeux humain. Med Afr Noire 16, 321-322 (in French).

Castro Ramos, M., Ayala, M., Errico, F. \& Silvera, F. V. (1998). Aislamiento de Mycobacterium bovis en Pinnipedos Otaria byronia (Lobo marino comun) en Uruguay. Rev Med Vet 79, 197-200 (in Portuguese).

Collins, D. M. \& Stephens, D. M. (1991). Identification of an insertion sequence, IS1081, in Mycobacterium bovis. FEMS Microbiol Lett 83, 11-15.

Collins, C. H., Yates, M. D. \& Grange, J. M. (1982). Subdivision of $M$. tuberculosis in five variants for epidemiological purposes: methods and nomenclature. J Hyg Camb 89, 235-242.

Corner, L. A., John, M., Bundesen, P. G. \& Wood, P. R. (1988). Identification of Mycobacterium bovis isolates using a monoclonal antibody. Vet Microbiol 18, 191-196.
Cousins, D. V. (1995). Tuberculosis in seals in Australia. In Proceedings of the Australian Veterinary Association Conference, pp. 51-57. Melbourne, Australia: Australian Association of Veterinary Conservation Biologists (AAVCB).

Cousins, D. V. (1996). Molecular epidemiology and diagnosis of Mycobacterium bovis and M. bovis-like organisms causing tuberculosis, pp. 1-317. PhD thesis, University of Western Australia.

Cousins, D. V., Wilton, S. D. \& Francis, B. R. (1991). Use of DNA amplification for the rapid identification of Mycobacterium bovis. Vet Microbiol 27, 187-195.

Cousins, D. V., Williams, S. N., Reuter, R., Forshaw, D., Chadwick, B., Coughran, D., Collins, P. \& Gales, N. (1993). Tuberculosis in wild seals and characterisation of the seal bacillus. Aust Vet J 70, 92-97.

Cousins, D., Williams, S., Liébana, E., Aranaz, A., Bunschoten, A. E., Van Embden, J. \& Ellis, T. (1998a). Evaluation of four DNA typing techniques in epidemiological investigations of bovine tuberculosis. J Clin Microbiol 36, 168-178.

Cousins, D. V., Skuce, R. A., Kazwala, R. R. \& van Embden, J. D. A. (1998b). Towards a standardized approach to DNA fingerprinting of Mycobacterium bovis. International Union Against Tuberculosis and Lung Disease, Tuberculosis in Animals Subsection. Int J Tuberc Lung Dis 2, 471-478.

Del Portillo, P., Murillo, L. A. \& Patarroyo, M. E. (1991). Amplification of a species-specific DNA fragment of Mycobacterium tuberculosis and its possible use in diagnosis. J Clin Microbiol 29, 2163-2168.

Edwards, U., Rogall, T., Blöcker, H., Emde, M. \& Böttger, E. C. (1989). Isolation and direct complete nucleotide determination of entire genes. Characterization of a gene coding for $16 \mathrm{~S}$ ribosomal RNA. Nucleic Acids Res 17, 7843-7853.

Espinosa de los Monteros, L. E., Galan, J. C., Gutierrez, M. \& 8 other authors (1998). Allele-specific PCR method based on pncA and $\operatorname{oxy} R$ sequences for distinguishing Mycobacterium bovis from Mycobacterium tuberculosis: intraspecies $M$. bovis pncA sequence polymorphism. J Clin Microbiol 36, 239-242.

Floyd, M. M., Guthertz, L. S., Silcox, V. A., Duffey, P. S., Jang, Y., Desmond, E. P., Crawford, J. T. \& Butler, W. R. (1996). Characterization of an SAV organism and proposal of Mycobacterium triplex sp. nov. J Clin Microbiol 34, 2963-2967.

Forshaw, D. \& Phelps, G. R. (1991). Tuberculosis in a captive colony of pinnipeds. J Wildl Dis 27, 288-295.

Gormley, E., Sandall, L., Hong, C., Lawton, D. \& Murray, A. (1997). Identification and differentiation of mycobacteria using the $\mathrm{P}_{\mathrm{AN}}$ promoter sequence from Mycobacterium paratuberculosis as a DNA probe. FEMS Microbiol Lett 147, 63-68.

Goulding, J. N., Stanley, J., Saunders, N. \& Arnold, C. (2000). Genome-sequence-based fluorescent amplified-fragment length polymorphism analysis of Mycobacterium tuberculosis. J Clin Microbiol 38, 1121-1126.

Grange, J. M. \& Yates, M. D. (1994). Guidelines for Speciation within the Mycobacterium tuberculosis Complex. WHO/Zoon/94.174. Geneva: World Health Organization Veterinary Public Health Unit.

Groenen, P. M. A., Bunschoten, A. E., van Soolingen, D. \& van Embden, J. D. A. (1993). Nature of DNA polymorphism in the direct repeat cluster of Mycobacterium tuberculosis; application for strain differentiation by a novel typing method. Mol Microbiol 10, 1057-1065.

Hunter, J. E., Duignan, P. J., Dupont, C., Fray, L., Fenwick, S. G. \& Murray, A. (1998). First report of potentially zoonotic tuberculosis in fur seals in New Zealand. N Z Med J 111, 130-131.

Huys, G., Rigouts, L., Chemlal, K., Portaels, F. \& Swings, J. (2000). Evaluation of amplified fragment length polymorphism analysis 
for inter- and intraspecific differentiation of Mycobacterium bovis, M. tuberculosis, and M. ulcerans. J Clin Microbiol 38, 3675-3680.

Kamerbeek, J., Schouls, L., Kolk, A. \& 8 other authors (1997). Simultaneous detection and strain differentiation of Mycobacterium tuberculosis for diagnosis and epidemiology. J Clin Microbiol 35, 907-914.

Karlson, A. G. \& Lessel, E. F. (1970). Mycobacterium bovis nom. nov. Int J Syst Bacteriol 20, 273-282.

Kirschner, P., Springer, B., Vogel, U., Meier, A., Wrede, A., Kiekenbeck, M., Bange, F.-C. \& Böttger, E. C. (1993). Genotypic identification of mycobacteria by nucleic acid sequence determination: report of a 2-year experience in a clinical laboratory. J Clin Microbiol 31, 2882-2889.

Liébana, E., Aranaz, A., Francis, B. \& Cousins, D. (1996). Assessment of genetic markers for species differentiation within the Mycobacterium tuberculosis complex. J Clin Microbiol 34, 933-938.

Morcillo, N., Bernardelli, A., Chirico, M. C. \& Dolmann, A. L. (2000). Colorimetric assay in comparison with MGIT system and the agar proportion method for determining MICs antimicrobial agents for Mycobacterium tuberculosis complex. In Abstracts of the World Congress on Lung Health and 10th ERS Annual Congress. September 2000, Florence, Italy.

Mostowy, S., Cousins, D., Brinkman, J., Aranaz, A. \& Behr, M. A. (2002). Genomic deletions suggest a phylogeny for the Mycobacterium tuberculosis complex. J Infect Dis 186, 74-80.

Niemann, S., Richter, E. \& Rüsch-Gerdes, S. (2002). Biochemical and genetic evidence for the transfer of Mycobacterium tuberculosis subsp. caprae Aranaz et al. 1999 to the species Mycobacterium bovis Karlson and Lessel 1970 (Approved Lists 1980) as Mycobacterium bovis subsp. caprae comb. nov. Int J Syst Evol Microbiol 52, 433-436.

Pfyffer, G. E., Auckenthaler, R., van Embden, J. D. \& van Soolingen, D. (1998). Mycobacterium canettii, the smooth variant of $M$. tuberculosis, isolated from a Swiss patient exposed in Africa. Emerg Infect Dis 4, 631-634.

Qian, L., Van Embden, J. D. A., van der Zanden, A. G. M., Weltevreden, E. F., Duanmu, H. \& Douglas, J. T. (1999). Retrospective analysis of the Beijing family of Mycobacterium tuberculosis in preserved lung tissues. J Clin Microbiol 37, 471-474.

Rogall, T., Flohr, T. \& Böttger, E. C. (1990a). Differentiation of Mycobacterium species by direct sequencing of amplified DNA. J Gen Microbiol 136, 1915-1920.

Rogall, T., Wolters, J., Flohr, T. \& Böttger, E. C. (1990b). Towards a phylogeny and definition of species at the molecular level within the genus Mycobacterium. Int J Syst Bacteriol 40, 323-330.

Romano, M. I., Alito, A., Bigi, F., Fisanotti, J. C. \& Cataldi, A. (1995). Genetic characterization of mycobacteria from South American wild seals. Vet Microbiol 47, 89-98.

Sreevatsan, S., Escalante, P., Pan, X. \& 11 other authors (1996). Identification of a polymorphic nucleotide in $\operatorname{oxy} R$ specific for Mycobacterium bovis. J Clin Microbiol 34, 2007-2010.

Sreevatsan, S., Pan, X., Stockbauer, K. E., Connel, N. D., Kreiswirth, B. N., Whittam, T. S. \& Musser, J. M. (1997). Restricted structural gene polymorphism in the Mycobacterium tuberculosis complex indicates evolutionarily recent global dissemination. Proc Natl Acad Sci U S A 94, 9869-9874.

Thierry, D., Brisson-Noël, A., Vincent-Levy-Frébault, V., Nguyen, S., Guesdon, J. L. \& Gicquel, B. (1990). Characterization of a Mycobacterium tuberculosis insertion sequence, IS6110, and its application in diagnosis. J Clin Microbiol 28, 2668-2673.

Thierry, D., Matsiota-Bernard, P., Pitsouni, E., Costopoulos, C. \& Guesdon, J. L. (1993). Use of the insertion element IS6110 for DNA fingerprinting of Mycobacterium tuberculosis isolates presenting various profiles of drug susceptibility. FEMS Immunol Med Microbiol 6, 287-297.

Thompson, P. J., Cousins, D. V., Gow, B. L., Collins, D. M., Williamson, B. W. \& Dagnia, H. T. (1993). Seals, seal trainers, and mycobacterial infection. Am Rev Respir Dis 147, 164-167.

Tsukamura, M., Mizuno, S. \& Toyama, H. (1985). Taxonomic studies on the Mycobacterium tuberculosis series. Microbiol Immunol 29, 285-299.

van Soolingen, D., Qian, L., de Haas, P. E. \& 7 other authors (1995). Predominance of a single genotype of Mycobacterium tuberculosis in countries of east Asia. J Clin Microbiol 33, 3234-3238.

van Soolingen, D., Hoogenboezem, T., de Haas, P. E. \& 9 other authors (1997). A novel pathogenic taxon of the Mycobacterium tuberculosis complex, Canetti: characterization of an exceptional isolate from Africa. Int J Syst Bacteriol 47, 1236-1245.

van Soolingen, D., van der Zanden, A. G. M., de Haas, P. E. W. \& 7 other authors (1998). Diagnosis of Mycobacterium microti infections among humans by using novel genetic markers. J Clin Microbiol 36, 1840-1845.

Veerman, G. M., Kelman, R., Colley, J. \& Pike, J. G. (1990). Rapid confirmatory identification of Mycobacterium bovis using a dot blotting immunodetection technique. Vet Microbiol 22, 335-340.

Vestal, A. L. (1975). Procedures for the Isolation and Identification of Mycobacteria, PHS no. 1547. Atlanta, GA: Centers for Disease Control.

Wayne, L. G. (1984). Mycobacterial speciation. In The Mycobacteria: a Sourcebook, pp. 42-43. Edited by G. P. Kubica \& L. G. Wayne. New York: Marcel Dekker.

Wells, A. Q. \& Oxen, D. M. (1937). Tuberculosis in wild voles. Lancet i, 1221.

Wells, A. Q. \& Robb-Smith, A. H. T. (1946). The Murine Type of Tubercle Bacillus (the Vole Acid-fast Bacillus) with Notes on the Morphology of Infection by the Vole Acid-fast Bacillus. London, UK: Medical Research Council.

Woods, R., Cousins, D. V., Kirkwood, R. \& Obendorf, D. L. (1995). Tuberculosis in a wild Australian fur seal (Arctocephalus pusillus doriferus) from Tasmania. J Wildl Dis 31, 83-86.

Zumárraga, M. J., Bernardelli, A., Bastida, R. \& 10 other authors (1999). Molecular characterization of mycobacteria isolated from seals. Microbiology 145, 2519-2526. 